\title{
Emotion, Gender and the Sustainability of Communities
}

\author{
Kerry Jeanne Tanner \\ Monash University $<$ Kerry.Tanner@sims.monash.edu.au $>$
}

\begin{abstract}
Emotional expression is the lifeblood of any organisation or community. This paper reviews recent approaches, research issues and trends in emotion research and then applies insights from this body of research to the area of community sustainability. A particular focus is the gendered nature of emotion and how emotion facilitates connections within communities. Utilising examples from the author's case study research in a women's community organisation in Melbourne, Australia, it contrasts the barren emotional landscape of many organisations with the vibrance and warmth of a feminist community organisation, and considers how ICTs may either facilitate or constrain this emotional expression. It draws implications on the vital role of emotion in sustaining communities.
\end{abstract}

\section{Background to the research}

The research reported here is part of a $\mathrm{PhD}$ study where a literature-based conceptual framework for organisational knowledge management was developed and tested in the e framework of selected organisational contexts. One of these is a case study of WIRE, a community organisation that provides a free information, support and referral service for women. Central concepts in my conceptual framework are human capital, knowledge ecology and the role of information and communication technologies (ICTs). The conception here of human capital is as a composite of intellectual capital, social capital and emotional capital. To date there has been relatively little understanding of the emotional capital dimension in organisational knowledge management. For the WIRE study, a case study protocol was devised and interviews were conducted with the WIRE manager, all of the paid staff, a board member, and several volunteers who staffed the phone service.

\section{Definitions of key concepts}

Community is used here in the sense of a social group with a defined identity, where people are linked by a common purpose, interest or commitment to a cause. Human connection is a key dimension of community and socio-emotional factors underpin these connections. The concept of community assumes interaction between people who, at some time, are collocated physically, or who may be collocated virtually through electronic links.

My focus on sustainability is primarily social sustainability, i.e. the nurturing and ongoing maintenance of healthy human connections that support the continuation of a community, but it does not exclude environmental sustainability as communities are embedded within a wider ecosystem upon which their continued existence depends. 
Emotion refers to a human inner feeling state; emotions are particular affective states, such as joy, sorrow, anger, fear, love, hate, trust. My emphasis is on how emotion affects social interaction within a community, and in particular the impact of status and gender on emotional expression within that community.

\section{Emotion Research: Approaches and Research Issues}

For millennia, philosophers have pondered human reason and emotion. In more recent times, emotion has been considered from several very different disciplinary perspectives: biology, psychoanalysis, psychology (cognitive psychology, social psychology), sociology, organisational theory, management and community studies. Biological researchers' focus on emotion is via observation of physiological responses to particular situations or stimuli (Ashkanasy, Härtel and Zerbe 2000, Ch.1; King, 2001; Stanley \& Burrows, 2001). Psychoanalysts explore the deeply embedded nature of human emotions such as anxiety within the context of the individual's life experience (Meyerson, 2000; Weiss \& Brief, 2001). Psychology for over a century has differentiated the three realms of thinking (or cognition), feeling (or affect or emotion) and acting (or behaviour), but until recently has focused much more on cognition and behaviour than on emotion (Fineman, 2001; Zerbe \& Härtel, 2000). Cognitive psychologists (eg Lazarus) typically subordinate emotion to cognition, whilst social psychologists consider emotion from a behavioural perspective, within the context of interpersonal interaction and social relationships (Stanley \& Burrows, 2001; Weiss \& Brief, 2001). Sociology, organisational theory, management and community studies also tend towards the relational view of emotion.

Levels of analysis in emotion research vary according to perspective, with emotion considered at individual, group, organisational or community levels (Waldron, 2000). Problems in researching emotion are widely noted - the difficulty in accessing what is a subjective experience; the limits of both selfdescription and observation of emotion; the overlapping nature of scales devised to measure emotion; and the complex interactions between emotion constructs that make it difficult to isolate particular effects (eg Davies, Stankov \& Roberts, 1998; Meyerson, 2000; Stanley \& Burrows, 2001; Zerbe \& Härtel, 2000).

Over the past fifteen years or so there has been a great resurgence in interest in the nature and role of emotion in work and community contexts, and a growing recognition of the centrality of emotion, and of particular emotions like trust, in making connections between people. Increasingly theorists are attempting to integrate insights from divergent perspectives, and are using the emotion lens to re-examine many aspects of organisational and community life (Stanley \& Burrows 2001). Researchers are experimenting with alternative ways to access emotion-for instance, narrative techniques such as storytelling and metaphor are becoming established as valuable adjuncts to more traditional research approaches (Ashkanasy \& Tse, 2000; Meyerson, 2000). This is particularly important with communities and disenfranchised groups.

Our interest here is research on the social and relational aspects of emotion within organisational and community settings, i.e. the socio-emotional aspects of community life. Much of this research is qualitative, within an interpretivist research paradigm. In the social constructionist approach, researchers focus on the role of emotion in how particular communities negotiate meaning through social processes, communication and discourse (Meyerson, 2000). The phenomenological approach explores emotion from the perspective of the individual embedded within a particular social context, and seeks to create a holistic picture of a situation through examining multiple perspectives and distilling those perspectives to derive meaning and understanding of a complex reality (eg historical and biographical narrative accounts) (Fineman, 2001). 


\section{The Major Themes and Debates in Recent Emotion Research}

\section{Cognition/Rationality and Emotion/Irrationality}

There has been a strong emphasis in Western philosophy to uphold reason and rationality over emotion-to view emotion as interfering with reason, and needing to be controlled or subdued. For most of the $20^{\text {th }}$ Century, Western management, organisational and sociological theories reflected this embedded assumption, with organisations in the Taylorist and Weberian traditions considered 'rational enterprises', where formal rules, processes, strategies and goals constrained the individual's emotionality/ 'irrationality' (Beyer \& Nino, 2001; Fineman, 2001; Meyerson, 2000). However, over time the concept of the rational enterprise was increasingly recognised as an incomplete or naïve view of organisations and organisational life. Herbert Simon (1955) introduced the notion of 'bounded rationality' in human decision-making in organisations and wrote extensively on this over several decades. Simon saw organisations as intentionally rational but 'bounded' by the constraints of human behaviour and organisational practices. Karl Weick (1979) and others continually emphasised the limitations of the rational model of enterprise, and the significance of social and emotional factors in organisational life. Mumby and Putnam (1992; Putnam \& Mumby, 1993) presented an alternative construct to Simon's 'bounded rationality' - that of 'bounded emotionality' where 'nurturance, caring, community, supportiveness, and interrelatedness are fused with individual responsibility to shape organizational experiences.' (Mumby \& Putnam, 1992, p. 465).

Unlike Western philosophy, Eastern thinking (eg the Chinese Yin and Yang) sees reason and emotion as inextricably intertwined and acknowledges the unity of opposites (Krone \& Morgan, 2000). The recent burgeoning interest in the emotional side of organisational and social life takes up similar themes-the fundamental importance of socio-emotional factors in organisations and communities; the interconnectedness in communities of feelings and cognition. Important research insights have been gained from qualitative research in non-Western and non-mainstream contexts.

\section{Emotion Taxonomies}

There is no single definitive taxonomy of human emotions and considerable debate concerning the number and kinds of distinct human emotions, and whether some emotions are more basic than others (Stanley \& Burrows, 2001). Some classifications isolate two or three main continuums of emotion (eg. positive-negative affect; pleasantness-unpleasantness; activation/arousal) whilst others identify a varying number (usually 7-11) of specific emotions. Izard's $(1977 ; 1992)$ seminal work from the biological perspective is widely cited in the emotion literature. His experimental work focused on isolating distinctive neuromuscular facial expressions in his subjects, which were linked to particular subjective feeling states. Izard claimed there were ten distinct categories of emotional expression evident across different cultures, with variations in intensity. There is some debate as to whether these emotions are distinct or overlapping, eg. brain circuitry research has shown just four distinct patterns associated with anger, fear, sorrow and joy. Duration of emotion state is another differentiator, with emotion, short-term and situation specific; mood, longer-term and more unfocused; and temperament, an enduring personality trait (Gray and Watson, 2001)

Other frameworks focus on the process of emotion - stages in an emotional response and how emotion relates to particular causes and consequences. Examples are Lazarus's Cognitive Appraisal Theory (Lazarus, 1966; 1982; 1984; 1991a; 1991b; Lazarus \& Cohen-Charash, 2001) and Affective Events Theory (Weiss \& Cropanzano, 1996; Basch \& Fisher, 2001).

\section{Emotion Labour/Emotion Work}

In The Managed Heart: Commercialization of Human Feeling (1983), Arlie Hochschild defined the concept of emotion work or emotion labour in terms of requirements or expectations at work to feign emotions that were not genuinely felt (eg. the forced niceness and inauthentic smile in a customer service 
interaction). She argued that emotion work alienates people from their emotions and creates a state of emotional dissonance between displayed emotions and actual feelings that over time, if not resolved, can have profound negative health impacts. As Lazarus and other stress researchers have demonstrated, personal emotional control is a significant element of psychological and physiological wellbeing. While more recent research has supported the broadly negative connotations of emotion labour, there is currently less of an 'all-or-nothing' view of it (Ollilainen, 2000). Mumby \& Putnam (1992) define emotional labour as 'the way individuals change or manage emotions to make them appropriate or consistent with a situation, a role, or an expected organizational behaviour.' Most professions have unwritten emotion display rules, eg. nurses being empathetic and caring; police or debt collectors showing anger and impatience (Rafaeli \& Sutton, 1991; Beyer \& Nino, 2001). At times, emotional detachment may be a functional way of coping with a very stressful or difficult job, eg. medical personnel dealing with death.

Emotion displays link closely with social cues, environment factors and job characteristics (eg Hackman \& Oldham, 1980; Humphrey, 2000). For instance, Rafaeli \& Sutton (1989; 1990) found that cashiers in supermarkets were less inclined to show positive emotions during busy times or when the supermarket was crowded than they were during slow times.

Emotion display rules are also strongly culturally embedded. In their research in Israeli and US retail agencies/ supermarkets, Rafaeli \& Sutton found very different customer service practices in relation to smiling at customers. A friendly smile/ display of positive emotion was expected of US customer service staff, whereas at Israeli supermarkets smiling was interpreted as inexperience - arguments and rudeness between customers and cashiers were the norm. Rafaeli (Rafaeli \& Sutton 1989) tells the following story about one of her observed cashier-customer interactions in an Israeli supermarket.

Customer: 'In America, all the cashiers smile.'

Cashier: $\quad$ 'So go to America. What do you want from me?'

(p. 635)

Van Maanen and Kunda (1989) explored emotional expression as a dimension of organisational culture. In their ethnographic research at Disneyland, they found emotion display rules/ emotion management was highly regulated and ritualised through the Disney culture and its embodiment through recruitment (i.e. attractive, young, educated whites), strong induction/ acculturation programs, codebooks regulating behaviour, and 'smile police' disguised as 'guests' to catch violators. They saw the 'dark side' of this culture management - $a$ form of social engineering focused on manipulating emotion and feelings, i.e. 'control of the heart' as well as the mind.

\section{Emotional Intelligence}

Building on Gardner's (1983) Theory of Multiple Intelligences, Salovey and Mayer (1990; Mayer \& Salovey, 1993) attempted to redefine intelligence in terms of what it takes to live life successfully. They identified five domains of personal intelligence that they labelled emotional intelligence: self-awareness; managing emotion and ensuring appropriateness of emotional expression; self-motivation and enthusiasm; recognising emotions in others; and social competence. In 1996, Goleman took up these ideas in his bestseller Emotional Intelligence: Why It Can Matter More Than IQ, popularising the notion of emotional intelligence and focusing attention on the importance of emotional factors in work and community contexts. Goleman argued that emotional intelligence is the major predictor of individual success in life and that it can be trained from childhood. He asserted that the emotionally adept, who know how to manage their own feelings well, and how to read and to deal effectively with others' feelings, are at an advantage in most areas of life.

The wave of popularity of emotional intelligence spawned a literature from consultants capitalising on the market for training managers and employees in how to hone their personal effectiveness skills to ensure personal success and enhanced organisational performance (Goleman 1998; Goleman, Boyatzis \& McKee 2002; Cooper \& Sawaf 1997; Weisinger 1998). Various tests and scoring systems for emotional intelligence have been devised, eg Cooper and Sawaf's EQ Map. 
Emotional intelligence has been linked with qualities of so-called 'transformational leaders' who facilitate 'transformational learning' in organisations (eg Bass \& Avolio, 1990; 1994a; 1994b; Tobin, 1996; Ashkanasy \& Tse, 2000). However, many are highly critical of this representation of organisational learning (eg Lakomski, 1995). Others make trenchant criticisms of the emotional intelligence construct and emotional intelligence tests and measures (eg Davies, Stankov \& Roberts 1998). Some question the validity of quantitative methods in accessing emotional dimensions.

Fineman (2000b) takes a rather different line of criticism:

It lies in the commodification of emotion-transforming emotion into a marketable product. ...The popularization of emotional intelligence presents emotion in a form that can be contained and 'sold', especially to the corporate world. ... Its manifest instrumentality and elitism (it can produce 'stars') and its supposed mutability ('raise your EQ') play on classic anxieties and promises, often with a clear managerialistic agenda. (p. 102)

\section{Emotional Ecology, Emotional Climate}

Emotion is a constant feature of social and relational environment that has a dramatic impact on organisational and community life, learning processes and performance. Frost et al (2000) have coined the term 'emotional ecology':

Organizations create an emotional ecology where care and human connection are enabled or disabled. ... That emotional ecology can facilitate or retard compassionate action.

(p. 26, 35)

This notion of emotional ecology is a particular application of broader concepts of organisational climate in the organisational theory, management and communications literatures, or learning climate in the organisational learning literature (eg Argyris, 1999; Senge, 1992; Tran, 1998). This research, spanning many decades has isolated a range of factors that contribute to positive/ supportive emotional climates, or to negative/ alienating emotional climates. In an earlier paper (Tanner, 2001) summarised key insights from these literatures and prepared a table differentiating features of a supportive versus an alienating emotional climate. Some of these factors included an environment characterised by high versus low levels of trust; optimism versus cynicism and fear; acceptance versus threat and judgmentalism; cooperation and mutual problem solving versus coercion and destructive competition; authenticity versus deception and hidden agenda; empathy and warmth versus cold detachment; valuing and respecting versus humiliating people; democracy versus authoritarianism; appreciation of diversity and divergent views versus intolerance; encouragement for experimentation versus blame for failure; engendering versus stifling creativity and innovation; motivating versus demotivating; and empowering versus disempowering.

The experienced emotional climate triggers self-reinforcing behaviour cycles, with stark differences between behaviour patterns engendered in supportive and alienating emotional climates. In supportive emotional climates, behaviours encouraged and reinforced include: ethical conduct and practice; open communication; cooperative team building; willing sharing of knowledge and resources; authentic/ emotionally honest patterns of behaving and relating to others; care and concern for others; a focus on action and goal achievement, active experimentation and exploring creative solutions; assertive communication and constructive negotiation.

In contrast, negative emotional climates engender active politicking-manipulative, deceitful and intimidating patterns of behaviour and unethical practices. Individual effort is focused on enhancing personal position and influence in a fiercely competitive environment, rather than on achieving organisational performance goals. Inevitably this process of personal aggrandisement involves undermining and destroying the perceived competition, assigning blame and discrediting others whilst concealing one's own agenda and mistakes. In the resultant 'survival-of-the-fittest' battleground, sabotage, retaliation, aggressive, abusive and threatening behaviour patterns, intimidatory tactics, and deceptive practices are rife. To survive in this hostile climate, people engage in a variety of self-protective behaviours. Trust vanishes and fear reigns supreme. 


\section{Emotion and learning}

Links have been made between a positive emotional environment based on trust and team learning, innovation and creative problem solving (De Dreu et al., 2001; Tran, 1998). In an environment of trust, people are more prepared to take risks that are necessary for learning by trial and error, and for the open sharing of knowledge and experience. Gabriel and Griffiths (2002) invite readers to contrast learning under a loved and respected teacher with learning under a hated teacher or cynical supervisor; or as part of an exciting team versus one torn with rivalries and acrimony. They write:

Learning in an organization which allows experimentation, innovation and failure is different from learning in an organization that values tradition, obedience and avoidance of failure at all costs. It is not the case that cynical managers, acrimonious groups and defensive organizations discourage learning. Far from it. What they do is to encourage a kind of learning that promotes defensive attitudes, conservatism and destruction of all new ideas as potentially threatening and subversive.

(Gabriel \& Griffiths, 2002, p.215).

\section{Emotion, Status and Gender}

Organisational politics and power plays have long been of interest to organisational and management theorists - manipulating emotion is the major control tool for those who aspire to power (Pfeffer, 1981; 1994). Fineman (2001, p. 228) claims that organisational cognitions 'are invariably embedded in politicized interests where emotionalized discourses prevail.' Within any organisation or community there is a continual dynamic interplay with status contests and power plays as individuals jockey for positions of influence within the wider social structure, and others within the structure cooperate, acquiesce, comply or resist.

A recent research focus has been on how emotional displays communicate status in organisations. Tiedens' experimental and field research into psychological factors in social position and status indicated a reciprocal relationship 'analogous to a vicious cycle' between emotions and social status (Tiedens, 2000, p. 72). She found that perceived social status influenced which emotions were experienced and the intensity of those emotions, and that emotional displays in turn reinforced existing patterns of high and low status. Anger, frustration and pride were emotions associated with a higher status partner/superior, and sadness, worry, guilt and appreciation with a lower status partner/subordinate. People tend to assume social status according to displayed emotions, i.e. an angry person is assumed to have high status whilst someone showing guilt to have low status. These are inaccurate perceptions with worrying implications, i.e. the angry are more likely to be promoted, a practice that institutionalises cycles of bullying or victimisation, high stress levels and pervasive job dissatisfaction (Tiedens, 2000).

Links between status and displayed emotion spill over to the gendering of emotion. In many traditional societies, there is the expectation that men will express their felt emotions freely whilst women suppress theirs. Härtel and Zerbe (2000) surmise that this is

because stereotypically masculine emotions are valued whereas stereotypically feminine emotions are often devalued. Consequently, organizational emotion display rules may result in greater risk of emotional exhaustion and psychological stress for women and persons occupying low status positions.

(p. 99)

Management and organisational theory has traditionally made an implicit association of cognitive/ rational elements with male emotions and emotional/ irrational elements with female emotions. In the bureaucratic ideal, emotion is subordinated to reason and 'male' attributes valued over the 'female'. Men are assumed to be rational, individually focused, driven to pursue their self-gratification, and women to be emotional, i.e. irrational, seeking connections through authentic interactions in communities that care (Meyerson, 2000). Gender rules are strongly embedded in culture. Those who demonstrate 'proper' or 
'appropriate' emotions for the particular culture are empowered and those who do not, typically are disempowered.

Critical feminist theory has developed alternative constructs to that of the 'rational enterprise'. Mumby and Putnam (1992; Putnam \& Mumby, 1993) deconstructed Simon's 'bounded rationality' which they see as a strongly male construct, centred around images of organisations as 'sites of domination and exploitation'. They argue that this patriarchal worldview has become the dominant paradigm for understanding organisational life and excludes or marginalises women as being, at most, in support services and nurturing roles. Mumby and Putnam (1992) present an alternative and feminist 're-reading' of organisational theory, and from this postulate 'bounded emotionality' as an equally valid construct.

In bounded emotionality, nurturance, caring, community, supportiveness, and interrelatedness are fused with individual responsibility to shape organizational experiences.

(p. 465).

Their purpose in articulating 'bounded emotionality' is not to offer it as the new dominant paradigm that excludes the rational paradigm, but in Derrida's sense to introduce 'a middle voice' or 'play of differences' that will encourage dialogue around deeper issues of structure, gender and emotion in organisational theory. In 'rational' paradigms, Mumby and Putnam argue that emotions or feelings have been devalued and trivialised, treated 'as either a weak and handicapped appendage to reason or as another "means" to serve organizational ends.' Here they are seeking understandings that are characterised by a tolerance of ambiguity; multiple voices co-existing in a socially fluid order; a flexible heterarchy rather than a hierarchy of goals; simultaneous focus on the individual and the 'linked fates' of all who comprise the organisation; and a strong sense of community and its interconnectedness. This approach emphasises the importance of the spontaneous expression of felt emotions (rather than emotion labour); and in developing effective listening and communication skills needed to promote mutual understanding.

As individuals share emotional experiences, their initial sense of anonymity gives way to feelings of community through the development of mutual affection, cohesion, and coherence of purpose.

However, as Mumby and Putnam explain below 'bounded emotionality' does not exclude rational elements:

By juxtaposing bounded rationality with bounded emotionality, we are not advocating that organizations abandon instrumental goals, productivity, or profit margins. Using bounded emotionality, in fact, does not call for a radical restructuring or tearing down of current organizational forms. Rather we propose to include what is currently ignored or marginalized, to change the context and ways of functioning in organizations, and to conceptualize organizations in different ways. Organizations do not need to sacrifice or lose sight of technical efficiency, but they should embed instrumental goals within a larger system of community and interrelatedness rather than concentrating on dominating the nature of the workplace.

More than a decade later, there has been increasing acceptance of the importance of community, collaboration, consensus building, communication and the so-called 'feminine' qualities of caring, nurturing and supportiveness. Communities of Practice, Knowledge Management and Community Informatics have these concepts as central pillars. As Bass \& Avolio (1994a) suggest, women's natural leadership styles may be better attuned than those of their male counterparts brought up with the "command and control' style of management, to achieve successful outcomes in this interconnected networked environment.

\section{The Role of Emotion and Gender in Sustaining Communities}

Worldwide, women play a central role in sustaining their communities, nurturing children, caring for family, the elderly and infirm. Their roles are more often voluntary rather than paid, and associated with the 'private' sphere rather than the 'public' sphere of paid work. When men leave a community for work or military service, women remain behind to sustain their families and communities. 
Funders of community development programs in developing countries are realising that program success is contingent on understanding the distinctive roles of men and women in their communities. The Food and Agriculture Organisation (FAO) (2004) recognises the crucial role played by women in the area of 'food and nutrition' at both household and community levels. Typically women tend the gardens; and gather, produce and prepare food for their families - they are the primary stakeholders in community nutrition and hygiene. Another example is the Pacific Peoples' Partnership (2004) that believes 'it is critical to understand the differential impacts on men and women of events, policies and development initiatives that affect them.' PPP claims that it has:

...worked consistently to support women as they work to enhance recognition of their vital and varied roles in communities, to strengthen their status and capacities as decision-makers, and to further their visions for sustainable livelihoods and futures.

The World Bank's Water and Sanitation Program (WSP) has isolated gender sensitivity as a key social factor in program sustainability over the longer term. A gender-sensitive approach is one that 'gives equal access to project inputs and processes relevant for the future service, such as information, training, new functions and jobs, and decision-making to both women and men', and that 'pays attention to the distribution of work, resources and benefits between women and men.' (Gross, van Wijk and Muhkerjee, 2001, p. 7) This often necessitates holding separate meetings, as women tend not to speak up when men are present. WSP has supported research into developing 'participatory tools' to help ensure the inclusion and participation of often excluded groups, especially women and the poor, at all stages of planning, implementation and ongoing operation of a water supply project (Lidonde, 2001). Gross, van Wijk and Muhkerjee (2001) undertook research into 88 WSP community-managed water supply projects across 15 countries. They summed up their findings as follows:

... projects that used more gender ... sensitive demand-responsive approaches had results that were better sustained. These communities also used their services more effectively, i.e. the majority used the improved water supply in a health-promoting manner. The findings also show that giving choices to more community groups - the poor, better off, women and men - and letting them influence (or control) the process of service establishment empowers them to later manage and sustain their services more effectively.

(p. v)

In the developed/ industrialised world where society has become increasingly atomistic, individualistic and intensely competitive, concern over rising rates of crime and social dysfunction has triggered interest in a need to rediscover or recreate community and social connections. In academic discourse, this is linked with the social capital debates of the last decade. Political scientist Robert Putnam (1993; 1995a; 1995b) defined social capital as features of social organization such as networks, norms, and social trust that facilitate coordination and cooperation for mutual benefit. The mutual benefits comprise 'the structure of the relationships, the interpersonal dynamics that exist within the structure, and the common context and language held by individuals in the structure.' . (Lesser, 2000, p. 4) In a recent symposium on social capital, Putnam (2004) presents the most important challenge for social capital as being 'to translate this concept from a framework for description into a framework for action.' Emotional intelligence is closely intertwined with social capital - it is the basis for the socio-emotional skills required in building social networks and sustaining communities.

One area of academic discourse particularly relevant to a consideration of emotion and gender in sustaining communities is eco-feminism. Bullis and Glaser (1992, p. 51) trace the origin of the term ecofeminism to Françoise d'Eaubonne who in 1974 argued 'that the current patriarchal system is incapable of creating a revolution which will stop the destruction of nature in time to avert total destruction.' The concept links oppression of women and other minority groups with the destruction of the environment by the dominant patriarchal regime. It links feminism with ecology, with the nature-based spirituality of ancient religions and matristic societies, and with Eastern rather than Western thought. Modernist 'rational' Western thought is a self-referential system that acknowledges nothing outside itself, and excludes the 'other' (Bullis \& Glaser, 1992, p. 55). Eco-feminism is a post-modernist approach that embraces the pluralism of many voices and seeks to redress oppression of women and minorities and the destruction of the environment. It sees the interconnectedness of life, and the central role that women play in facilitating 
those connections through nurturance and building of community. Bullis and Glaser suggest that ecofeminism is a useful concept for envisioning alternative models of organisational change-models that focus on connections between people, listening and alternative forms of organising. Gaard (2001) applies eco-feminist concepts to illuminating the current water crisis. She contrasts 'the way in which gendered, cultural assumptions about water, power, and human relations have led to creating a water-power infrastructure that perpetuates environmental sexism, environmental racism and environmental classism' with 'an eco-feminist approach to water justice' that 'advocates strategies for bringing about an ecological democracy, an ecological economics, and a partnership culture in which water and energy flow freely.' (Gaard, 2001, p. 157).

Some of the more recent writings on eco-feminism adopt a more pragmatic and less idealised or utopian stance - acknowledging that Western rationalist thought is embedded in our systems and that ecofeminist thinking can be blended and can co-exist with traditional systems. Ashcraft (2001) argues for a compromise or hybrid organisational form, a 'feminist bureaucracy' that blends hierarchical and egalitarian models. She observes that purely feminist, collectivist organisational forms have proven difficult to sustain over the longer term, and that it is possible to balance the rational and emotional, the professional and the personal. Ashcraft proposes a type of 'organised dissonance' where opposites (eg centralisationdecentralisation; equality-inequality; leading-following) co-exist in a dialectical tension and are kept 'in play'. Her feminist bureaucracy 'accents the neglected role of emotion in empowerment' and 'reclaims emotion as part of rationality' (Ashcraft 2001, pp. 1315-1316). MacGregor (2004) highlights the 'political risks' of an eco-feminism that reduces women's role to 'care' - that entrenches traditional sexist views, the exploitative division of labour and devaluation of women's work. She argues that eco-feminism needs to broaden its perspective to include 'women as political actors' based on 'feminist theories of citizenship.'

Reed (2003) takes a very different perspective on eco-feminist issues in her book Taking Stands: Gender and the Sustainability of Rural Communities. Rather than presenting the environmentalist case for preventing logging in the temperate rainforests of British Columbia, she tells the personal stories of women from these rural logging communities who are fighting for the preservation of their families' livelihood and their communities. Her focus is 'women's anti-environmental activism', exploring gendered relations 'beyond the front lines of political protest'. In the Preface, Reed explains that her central thesis is that 'environmentalism is an important social challenge' and that 'social considerations must accompany demands for changes in human-ecological relations.' She aims to demonstrate the limitations of dichotomous 'pro' and 'anti' thinking 'that currently polarize environmental debates', and to reveal the wider picture, because:

Only through a heightened understanding of these processes can we address problems of mutual concern that link a politics favouring environmental protection with a politics that supports social justice.

(Reed 2003, p. x).

\section{Insights from a Community Organisation Case Study}

\section{WIRE-Women's Information}

WIRE is a free information, support and referral service for women, located in the Melbourne central business district. Established in 1984 as the Women's Information and Referral Exchange (WIRE), it now prefers to use the more explicit name 'Women's Information'. Its origins derive from an initiative of organisations including the Women's Electoral Lobby, Lifeline, the Victoria Police and the YWCA that saw the need for a specific community organisation to deal with complex queries from women seeking support that these organisations could not provide. Women had many questions concerning major life choices and their basic human rights and were seeking support and information to help them in their quest for solutions.

Twenty years later, WIRE has evolved into a comprehensive information, support and referral service. The inaugural service area was the telephone service, staffed by women volunteers. This is still the backbone of the service, involving 60-80 volunteers. However, the service has diversified over the past few 
years to comprise also an online service (i.e. an Internet presence and responses to email inquiries) and a 'walk-in' central city information centre - the Women's Information Centre (WIC), opened in 1999.

Through its telephone service, WIC and online information, WIRE aims 'to empower women to make confident choices for themselves.' WIRE provides information and referral on a wide range of issues such as family life and relationships, separation, domestic violence, discrimination, self-esteem, depression, health and well-being, housing, employment, finance, education and legal issues. It has an extensive community information database from which referrals are made to a wide range of community organisations, self-help groups and individual practitioners such as female doctors, lawyers, counsellors and tradeswomen. WIRE aims to be accessible to women across Victoria and to provide them with services of the highest possible quality, delivered in a way that acknowledges and validates their experiences.

\section{Emotion and Gender at WIRE}

\section{Balancing Rational and Emotional Elements}

WIRE is a community organisation that manifests a skilful blending of rational and emotional elements. It was founded on a collective governance model, which suited its driving feminist philosophy and mission of 'empowering women to make confident choices for themselves' or 'strong, empowered women in control of their lives.' The service is committed to social change, active learning and respect of diversity. However, the very egalitarian collectivist model, as Ashcraft (2001) has observed, may not be viable over the longer term. At WIRE, slow decision-making processes proved frustrating and constrained rapid response to changing environmental conditions.

In the late 1990s, under pressure from the prevailing State government with its strongly economic rationalist approach and demands for greater accountability from community organisations, WIRE adopted a modified corporate model of governance, with an honorary board of elected representatives to develop strategy. As the manager explained, in developing the new structure there was 'a conscious effort to maintain the collaborative and participatory elements' that were an integral part of the WIRE culture. Major strategic challenges have been 'building public recognition and awareness, and dealing with the emergence of new technologies that can make the operation more efficient.' After a few initial 'teething problems' with the new governance model, it is now working well.

The effective intertwining of rational and emotional elements is most clearly evident in WIRE's excellent training programs. Like most voluntary organisations, WIRE has to deal with a rapid turnover of volunteers, and, to a lesser extent, staff. This necessitates a well-developed training program and effective processes for screening applicants and trainees. WIRE delivers its basic training for volunteers twice annually, for three hours weekly over 13 weeks. In addition, trainees undertake a phone shift each week. The training sessions provide a thorough grounding in the feminist framework, the WIRE culture, developing self-awareness, counselling skills and more technical skills such as using the WIRE community information database and information resources and mastering specific work processes and routines. There is a strong focus on developing attitudes of tolerance and acceptance of diversity. Volunteers have ample opportunity to model the expected behaviours in a non-threatening climate, and receive feedback from the trainer and colleagues on how they are handling a difficult situation. The trainer's story and explanation below illustrate the approach and techniques used in training volunteers, and show the crucial importance of dealing effectively with emotion - and how emotions are 'honoured' at WIRE.

[In training] we work in a reflective team model ...-it's ... about listening to each other and connecting...... [being] able to listen to a woman's story and make an assessment about what the issues are and what sort of information and referrals that she needs. ... We do a lot of personal reflection on 'who I am' and 'what I bring to the work' and 'how I influence the work' as well. ... So for example I was on [a phone shift] with a trainee doing an evaluated call. She was a very corporate, tough, young woman and she was talking to a woman for a brief period and she said 'Can I put you on hold?' and she turned around and I said 'What's happening?' and she said 'She's crying. What do I do?' I said 'Well, she's crying and you put her on hold!' And she said 'Yep.' And I said 'Well you'd better quickly get her off hold before you lose her' and so she went back in. We worked on it and at the end of the call. I said 'What do you know 
about crying?' and she said 'We're just not allowed to cry in our family. Nobody cries in front of each other. It seems quite a humiliating experience.' So that was a clear example about her developing some awareness about how she is going to limit a call where someone is crying.

\section{Emotional Intelligence}

WIRE's effective processes for screening applicants and sifting out unsuitable trainees early on, combined with the nature and thoroughness of the training program, tend to ensure that the majority of those who end up working at WIRE as staff or volunteers exhibit at least several of the traits associated with 'emotional intelligence'. While certain aspects of emotional intelligence are arguably enduring personality traits, others can be enhanced or developed through training. Excerpts from the trainer's interview above clearly demonstrate how self-awareness (understanding and monitoring one's own emotions, motivations and reactions); ensuring appropriateness of emotional expression; being empathetic, caring and able to recognise emotions in others; and social competence are developed over a period of several months in training and from experience with clients in the Phone Room. One volunteer expressed how this worked for her in relation to developing empathy for the caller:

Listening is the first and most important skill. Empathy and apart from hearing the tone in the voice also feeling it. I found from very early on, after a year or so, to actually feel it without it reacting on myself — but you actually feel their pain.

Both staff and volunteers clearly recognised their own and others' personal development or transformation at WIRE, as indicated in the following comments:

The WIRE women here are independent and make decisions for themselves. [I don't know where I'd be now] if I hadn't come to WIRE-because I have seen so much injustice and discrimination in my lifetime. When I talk to the younger girls [volunteers] during calls, you can see them changing - they are empowered and informed. We are doing it in the Phone Room too [with callers]. ... When you see the blooming of the WIRE workers.... I remember one in particular-when she came here she was very nervous but stuck it out. She became a Team Leader because she was very good on the phone, with empathy and was very good to callers. ... She just bloomed from then on. That's a couple of years ago and she's still here- you can see it. It has empowered her so much. When women leave and go out there they are handling their situations differently, are more pro-active and supportive of women and understanding. [Older volunteer]

[The training was] very confronting at a personal level. Before I did the WIRE training I actually thought that I was quite a good communicator. But half way through the WIRE training I actually realised that in fact I had a lot of work to do as far as communicating, because I realised that my 'listening' wasn't always there. So it was amazing that you kind of think you've got to go back and re-learn how to communicate. ... I find myself thinking I've been to tertiary level education and still no one tells you [about listening]. You don't get taught that. ... So I had to take a step back and look at the way people communicate on a daily level. People don't listen to what you're saying. [Younger volunteer]

\section{Emotion Labour}

Perhaps the most eloquent description of 'emotion labour' was given by one volunteer (about 30 years old). In the following interview excerpt she is contrasting her experience in paid work in the corporate and retail sectors with her WIRE experience.

It's the first time in my life that I've been in a work situation where you're encouraged to be yourself. I guess my work experience history has not always been in an environment where I've been able to really be myself. I've always had to fit some prototype-whether it's corporate or retail. It is amazing to actually be in an environment in which you come in and intellectually have your ideas heard and be validated and be supported and if there is a debate going on it is in 
such a respectful manner-so it's just that old fashioned common courtesy and respect which I think a lot of work places don't have any more.

I guess WIRE actually acknowledges that whole human aspect of just being human. I found in the past with my work history you have to go in and actually hang up your personality on the front door to survive. If you're slightly political, if you're slightly assertive or outspoken and it's not the norm it's not accepted. It's just been amazing to be in that environment [and now at WIRE] working amongst women has been quite incredible-the way that things are done differently.

Women listen and they allow space just for ideas to flow and they don't frown upon emotions as having a negative connotation. Diversity isn't a problem amongst women, whereas men are threatened by diversity because they don't understand it, or that's been my experience within the workplace. I approached my employer at the time and said I'd like to cut my hours. That was all OK and they were a bit shocked that I was doing it for voluntary work. They didn't really understand why I would give up [paid] work for voluntary work.

\section{Emotional Climate/ Emotional Ecology}

Several of the comments quoted above say a great deal about the emotional climate at WIRE. It is, to paraphrase Frost et al. (2000), 'an emotional ecology where care and human connection are enabled'-a place of 'organisational compassion' where staff and volunteers reach out to establish 'emotional connections' of empathy and warmth. It stands in stark contrast to the emotional climate of many organisations.

In the following comments, staff describe their experience of the emotional climate at WIRE.

Within WIRE we are very much working in a team atmosphere.... It is very supportive and collaborative; an atmosphere of helping and supporting each other. ...Compared with business organisations, we are relaxed. And we are a bunch of women working together as well; there is no ego involved which makes a lot of difference. It is very relaxing and ... there is such a difference from the corporate world.

WIRE has an interesting culture. I guess it is basically about celebrating diversity and it works on a feminist framework. However, I have interacted with other organisations which operate on a feminist framework but what is great about WIRE is that it brings it back down to day-to-day living. So for me I think the way I would describe it is 'common respect' and celebrating diversity-and encouraging people to be themselves and supporting women through their decisions whatever they might be-and about not judging.

And from one of the volunteers:

I have found it wonderful because the support we get within WIRE. There is such a diversity of cultures as well and that's a great learning experience for all of us. It's wonderful to be with these women, all linked together without discrimination or judgements.

\section{ICTs and emotional factors at WIRE}

WIRE established a Web presence on VICNET in 1995. Subsequently its site has moved to other specialist third-party service providers who target 'resource-poor' community organisations. Currently WIRE is using a Linux-based open source integrated groupware product, PHProjekt for its intranet and to enhance the interactivity of its web service delivery. On its site, WIRE has links to 'information sheets' on key topics eg. what to do when faced with domestic violence or sexual assault. Hits on the WIRE site have risen exponentially whilst usage of the phone service has remained fairly constant. One issue with going online has been how a local state-based service can deal with the growing reach of the service to a global audience. WIRE now lists prominently on its site its geographical location in Victoria, Australia, so that it 
is not raising unrealistic expectations that it can make referrals or answer email queries from for example, India or America.

Our research at WIRE highlighted several links between ICTs and emotional factors. The following comments and excerpts from interviews with WIRE staff and volunteers show how available technology can simultaneously both facilitate and constrain human interaction and emotional expression.

Staff reflected on patterns of usage of its web-based information, eg. where there is a high level of embarrassment about an issue, many women prefer the anonymity that comes with using online information or anonymous email contact:

'Women use it ... a lot on sexual assault cases. Sexual assault is an issue that for some women it is easier to do on-line than talk to someone or go somewhere.

The increasing popularity of email queries has highlighted issues about the appropriateness of the medium to deal adequately with the highly emotive content of many messages.

Some requests you can't deal with by email I think. You have to ask them to ring the phone service because you need to talk about it. It is very hard talking by email. You need to get her to contact the phone service because there is someone there who can listen and advise and talk about things, because it is too complex for email. ... the emails show that women want answers to quite complex issues which are really not appropriate for email.

It's easier over the phone because you've got a dialogue with someone-you've got so much more scope with your voice; you can use inflections - you can listen and ask pertinent questions. In an email you really have none of that and there are a few kind of funny signs that you can use but they are really not appropriate in a supportive relationship.

Nonetheless, email appears to offer women a confidential space for serious issues they do not feel comfortable talking about directly.

Quite a few of the emails are slanted towards sexual assault issues and violence. So they obviously feel safer in email maybe and not really talking to someone about it.

I think it is interesting with our emails that ... a lot of the issues and queries that women have are about the hard stuff - like they are in crisis, or it's about domestic violence and sexual assault. In some way email is offering them the secrecy and the confidentiality that may be they are not comfortable with talking to someone over the phone.

At the walk-in Women's Information Centre, there are computers available for public use, and a staff member is available to assist or train women in using the Internet. Staff told stories about how women who were very apprehensive about the new technology gradually gained in confidence in this supportive, nonthreatening environment. Over time they felt a sense of liberation and empowerment, with new horizons and communication opportunities opened to them.

Older women, even women in their seventies come every week to learn a bit more about the Internet. They find it very exciting and learn how to correspond with their grandchildren and understand what they are on about.

Any suggestion that WIRE's phone service may adopt more sophisticated call centre technology was abhorrent to staff and volunteers - the very antithesis to what WIRE stood for.

Do we want to become a call centre? No! ... I have two friends who have worked in call centres for ages and it's a working dog's breakfast-high pressure, statistics, statistics, statistics. You know, you get questioned if you have been in non-call mode for five minutes to go to the toilet. That's not what WIRE wants to achieve I think. I don't see the sort of service that WIRE provides being converted into a call centre environment. Although I do know that the phone centre technology is state-of-the-art, but is purely for a corporate attitude and not for a community attitude. 
One volunteer reflected that reliance on technology and static information in the database did not necessarily address the human needs of callers.

It's a terrible thing to say but I almost don't have faith in the database. It's not as if it isn't good or anything like that—which it is. It's just that detachment and ... lack of sensitivity.

She went on to explain what she meant by an analogy to the use of CAD tools in design of furniture and buildings:

I guess I'm going away a bit from the WIRE thing but with CAD (Computer Aided Design), that's just fantastic for technical drawings, but as far as designing I think it limits your designing ability. It's a bit like your crisis call-you need that interaction to get your full potential. Because CAD has been around for so many years now there are a lot of people who are designing on CAD. You know it's funny because I'll sometimes look at the way product design goes in buildings. You can see it-you can see the progression. You can see the technology speaking into the design. I find that totally fascinating and it's interesting because to a certain extent I take that a step further and I think that human service is going to go that way too if it's going to be rationalised through technology. I think that it's very limiting. But it is happening. [It's quite parallel in the Phone Room] because you are dealing with emotions and you're dealing with human interaction as opposed to straight information.

Similar sentiments were expressed by a staff member who stressed that WIRE's services were much more than a matter of providing specific chunks of information from a database, that human contact was the integral component:

[It is ]a wise thing to have human contact ... [What] it comes down to is [this] - Is information just a number, or is it about exploring what a woman's story is? Because information as an end point [emphasises] ... the idea that it is a goal. I actually don't think it is. It is actually about a process, a process of going through stuff to have that validated and to have that clarified. Often you'll find that if a woman is calling - and this is a common thread whether it is phone or email or face-to-face - often a woman comes in with a problem and when she starts exploring it, a whole lot of other things come up as well. We'll go somewhere completely different, and there is that process of that sounding board actually speaking about what your needs are that actually make it real.

In applying ICTs in community organisations, it is important to realise their capacity both to facilitate and to constrain emotional expression. The link found here between perceived embarrassment and the need for anonymous communication is interesting, and contrasts with other situations where 'richer' communication channels are sought. There are distinct socio-emotional dimensions of each communication channel (face-to-face, phone, email, internet), and it is important to know the most effective medium for particular emotive content. However, this is compounded by individual differences, i.e. not all people react the same way. Individual perception of a situation will impact on choice of communication medium. For example, in some instances where clients felt more comfortable with email, staff felt constrained and unable to respond as adequately as they could if they were able to use the phone to communicate empathy and negotiate meaning.

Acquiring computer and Internet skills imbued many women with a growing sense of confidence and personal empowerment. Also it opened up new communication possibilities, for example in overcoming a generational barrier and facilitating dialogue with grandchildren.

By the time staff and volunteers had completed their training at WIRE, they had developed sound computer skills. However, there was an evident ambivalence for some in relation to the technology. While they recognised and appreciated its value in enabling new service options they also feared the spectre of technological determinism, i.e. that the technology could undermine the expression of human compassion and warmth that was fundamental to WIRE's service philosophy. The notion was not easy for interviewees to articulate, and they used stories and analogies to communicate their concerns. These were sometimes expressed in terms of a contrast between corporate and community values, and linking 'rationalising 
through technology' with pressured corporate environments, and communicating care and compassion through dialogue with community organisations. There are clear gender overtones in this discussion.

\section{Conclusion}

In Western thought for centuries, emotion has been subordinated to reason as something that must be subdued and controlled. Only over the past few years has there been a concerted attempt to restore emotion as an 'equal partner' in the traditional tripartite division of cognition (thinking), -emotion (feeling), and behaviour (acting), and to acknowledge the intertwined nature of all three. In organisational, management and community literatures, there is growing recognition of the centrality of emotional factors in making and sustaining connections between people and communities. The recently popularised concept of 'social capital' has strong connections with the relational aspects of emotion and 'emotional intelligence'. More attention is being paid to the need to minimise the negative consequences of emotion labour, to foster authenticity of emotional expression and the development of positive emotional climates that support learning and human wellbeing.

Embedded links of emotion with status and gender have been explored, and increasingly there is recognition of the need to restore balance by giving more value to the so-called 'feminised' forms of emotional expression. Caring, nurturing, supportiveness, collaboration and acceptance of diversity play a crucial role in building communities and sustaining community life.

Community organisations like WIRE have succeeded in effectively blending rational and emotional elements and in creating warm, vibrant, sustainable communities - a goal that businesses seek to emulate (eg. through developing communities of practice) but find elusive. A key factor contributing to WIRE's success is its 'honouring of emotion'-its emphasis on authentic emotional expression, affirmation of the individual, trust, respect for diversity, and strong core values that are effectively culturally embedded and inspire passion and commitment. This underpins the close links and effective strategic networks that have supported WIRE through difficult times and continue to sustain it. It stands in stark contrast to the barren emotional landscapes of many large organisations 'where you have to hang up your personality on the front door to survive.' 


\section{References}

Argyris, C. (1999). On organizational learning. 2nd ed. Oxford: Blackwell Business.

Ashcraft, K. L. (2001). Organized dissonance: Feminist bureaucracy as hybrid form. Academy of Management Journal, 44(6), Dec., pp. 1301-1322.

Ashkanasy, N. M. \& Tse, B. (2000). Transformational leadership as management of emotion: A conceptual review. In N. M. Ashkanasy, C. E. J. Härtel, \& W. J. Zerbe, (Eds.). Emotions in the workplace: Research, theory and practice. (pp. 221-235). Westport, CT: Quorum Books.

Ashkanasy, N. M., Härtel, C. E. J., \& Zerbe, W. J. (2000). Emotions in the workplace: Research, theory and practice. In N. M. Ashkanasy, C. E. J. Härtel, \& W. J. Zerbe, (Eds.). Emotions in the workplace: Research, theory and practice. (pp. 3-18). Westport, CT: Quorum Books.

Ashkanasy, N. M., Härtel, C. E. J., \& Zerbe, W. J. (Eds.). (2000). Emotions in the workplace: Research, theory and practice. Westport, CT: Quorum Books.

Basch, J. \& Fisher, C. D.(2000). Affective events-emotions matrix: A classification of work events and associated emotions. In N. M. Ashkanasy, C. E. J. Härtel, \& W. J. Zerbe, (Eds.). Emotions in the workplace: Research, theory and practice. (pp. 36-48). Westport, CT: Quorum Books.

Bass, B. M. \& Avolio, B. J. (1990). The implications of transactional and transformational leadership for individual, team, and organization development. Research in Organizational Change and Development, 4, pp. 231-272.

Bass, B. M. \& Avolio, B. J. (1994a). Shatter the glass ceiling: Women may make better managers. Human Resource Management, 33, pp. 549-560.

Bass, B. M. \& Avolio, B. J. (Eds.) (1994b). Improving organizational effectiveness through transformational leadership. Thousand Oaks, CA: Sage.

Beyer, J. \& Nino, D. (2001). Culture as a source, expression and reinforcer of emotions in organizations. In R. L. Payne \& C. L. Cooper (Eds.). Emotions at work: Theory, research and applications in management. (pp. 173-197). Chichester, England: Wiley.

Bullis, C. \& Glaser, H. (1992). Bureaucratic discourse and the goddess: Towards an ecofeminist critique and rearticulation. Journal of Organizational Change Management, 5(2), pp. 50-60.

Cooper, R. K. \& Sawaf, A. (1997) Executive EQ: Emotional intelligence in business. London: Orion Business Books.

Davies, M., Stankov, L. \& Roberts, R. D. (1998). Emotional intelligence: In search of an elusive construct. Journal of Personality and Social Psychology, 75(4): pp. 989-1015.

De Dreu, C. K. W., West, M. A., Fischer, A. H. \& MacCurtain, S. (2001). Origins and consequences of emotions in organizational teams. In R. L. Payne \& C. L. Cooper (Eds.). Emotions at work: Theory, research and applications in management. (pp. 199-217). Chichester, England: Wiley.

Fineman, S. (Ed.). (2000a). Emotion in organizations. 2nd ed. London; Thousand Oaks, CA: Sage Publications.

Fineman, S. (2000b). Commodifying the emotionally intelligent. In S. Fineman (Ed.). Emotion in organizations. 2nd ed. (pp. 101-114). London; Thousand Oaks, CA: Sage Publications.

Fineman, S. (2001). Emotions and organizational control. In R. L. Payne \& C. L. Cooper (Eds.). Emotions at work: Theory, research and applications in management. (pp. 219-237). Chichester, England: Wiley.

Food \& Agriculture Organization (FAO). (2004). Food and nutrition. Available: http://www.fao.org/DOCREP/005/Y3969E/y3969e03.htm Accessed 15 August, 2004. 
Frost, P. J., Dutton, J. E., Worline, M. C. \& Wilson, A. (2000). Narratives of compassion in organizations. In S. Fineman (Ed.). Emotion in organizations. 2nd ed. (pp. 25-45). London; Thousand Oaks, CA: Sage Publications.

Gaard, G. (2001). Women, water, energy: An ecofeminist approach. Organization \& Environment, 14(2), June, pp. 157-172.

Gabriel, Y. \& Griffiths, D. S. (2002). Emotion, learning and organizing. The Learning Organization, 9(5), pp. 214-221.

Gardner, H. (1983). Frames of mind: The theory of multiple intelligences. New York: Basic Books.

Goleman, D, Boyatzis, R. \& McKee, A. (2002). Primal leadership: Realizing the power of emotional intelligence. Boston, MA: Harvard Business School Press.

Goleman, D. (1996). Emotional intelligence: Why it can matter more than IQ. London: Bloomsbury.

Goleman, D. (1998). Working with emotional intelligence. New York: Bantam Books.

Gray, E. K. \& Watson, D. (2001). Emotion, mood, and temperament: Similarities, differences and a synthesis. In R. L. Payne \& C. L. Cooper. (Eds.). Emotions at work: Theory, research and applications in management. (pp. 21-43). Chichester, England: Wiley.

Gross, B., van Wijk, C. \& Mukherjee, N. (2001) Linking sustainability with demand, gender and poverty: A study in community-managed water supply projects in 15 countries. Washington, DC: The World Bank Water and Sanitation Program. Available: http://www.wsp.org/publications/global_plareport.pdf Accessed 15 August, 2004.

Hackman, J. R. \& Oldham, G. R. (1980). Work redesign. Reading, MA: Addison-Wesley.

Härtel, C. E. J.\& Zerbe, W. J. (2000). Commentary: Emotions as an organizing principle. In N. M. Ashkanasy, C. E .J. Härtel, \& W. J. Zerbe, (Eds.). Emotions in the workplace: Research, theory and practice. (pp. 97-100). Westport, CT: Quorum Books.

Hochschild, A. R. (1983).The managed heart: Commercialization of human feeling. Berkeley, CA: University of California Press.

Humphrey, R. H. (2000). The importance of job characteristics to emotional displays. In N. M. Ashkanasy, C. E. J. Härtel, \& W. J. Zerbe, (Eds.). Emotions in the workplace: Research, theory and practice. (pp. 236-249). Westport, CT: Quorum Books.

Izard, C. E. (1977). Human emotions. New York: Plenum Press.

Izard, C. E. (1992). Basic emotions, relations among emotions, and emotion-cognition relations. Psychological Review, 99, pp. 561-565.

King, M. G. (2001). Emotions in the workplace: Biological correlates. In R. L. Payne, \& C. L. Cooper. (Eds.). Emotions at work: Theory, research and applications in management. (pp. 85-106). Chichester, England: Wiley.

Krone, K. J. \& Morgan, J. M. (2000). Emotion metaphors in management: The Chinese experience. In S. Fineman (Ed.). Emotion in organizations. 2nd ed. (pp. 83-100). London; Thousand Oaks, CA: Sage Publications.

Lakomski, G. (1995). Leadership and learning: From transformational leadership to organisational learning. Leading \& Managing, 1(3), pp. 211-225.

Lazarus, R. S. \& Cohen-Charash, Y. (2001). Discrete emotions in organizational life. In R. L. Payne \& C. L. Cooper. (Eds.). Emotions at work: Theory, research and applications in management. (pp. 45-81). Chichester, England: Wiley.

Lazarus, R. S. (1966). Psychological stress and the coping process. New York: McGraw-Hill.

Lazarus, R. S. (1982). Thoughts on the relations between emotions and cognition. American Psychologist, 37, pp. 1019-1024. 
Lazarus, R. S. (1984). Stress, appraisal, and coping. New York: Springer.

Lazarus, R. S. (1991a). Emotion and adaptation. New York: Oxford University Press.

Lazarus, R. S. (1991b). Progress on a cognitive-motivational-relational theory of emotion. American Psychologist, 46, pp. 819-834.

Lesser, E. L. (Ed.) (2000). Knowledge and social capital: Foundations and applications. Boston: Butterworth Heinemann.

Lidonde, R. (2001). Gender and participation. 27 th WEDC Conference, People and Systems for Water, Sanitation and Health, Lusaka, Zambia, 2001, pp. 110-112. Available: http://www.lboro.ac.uk/wedc/papers/27/5\%20-\%20Institutional\%20Issues/11\%20-\%20Lidonde.pdf Accessed 15 August, 2004.

MacGregor, S. (2004). From care to citizenship: Calling ecofeminism back to politics. Ethics and the Environment, 9(1), Spring, pp. 56-84.

Mayer, J. D. \& Salovey, P. (1993). The intelligence of emotional intelligence. Intelligence, 17, pp.443-450.

Meyerson, D. E. (2000). If emotions were honoured: A cultural analysis. In S. Fineman (Ed.). Emotion in organizations. 2nd ed. (pp. 167-183). London; Thousand Oaks, CA: Sage Publications.

Mumby, D. K. \& Putnam, L. L. (1992). The politics of emotion: A feminist reading of bounded rationality. Academy of Management Review, 17(3), pp. 465-486.

Ollilainen, M. (2000). Gendering emotions, gendering teams: Construction of emotions in self-managing teamwork. In N. M. Ashkanasy, C. E.J. Härtel, \& W. J. Zerbe, (Eds.). Emotions in the workplace: Research, theory and practice. (pp. 82-96). Westport, CT: Quorum Books.

Pacific Peoples Partnership. (2004). Women in the South Pacific. Available: http://www.pacificpeoplespartnership.org/archives/000010.html Accessed 15 August, 2004.

Payne, R. L. \& Cooper, C. L. (Eds.). (2001). Emotions at work: Theory, research and applications in management. Chichester, England: Wiley.

Pfeffer, J. (1981). Power in organizations. Boston: Pitman.

Pfeffer, J. (1994). Managing with power: Politics and influence in organizations. Boston: Harvard Business School Press.

Putnam, L. L. \& Mumby, D. K. (1993). Organizations, emotion and the myth of rationality. In S. Fineman (Ed.).Emotion in organizations. London: Sage Publications.

Putnam, R. D. (1993). Making democracy work: Civic traditions in modern Italy. Princeton, NJ: Princeton University Press.

Putnam, R. D. (1995a). Bowling alone: America's declining social capital. Journal of democracy, 6, pp. 6578.

Putnam, R. D. (1995b) Tuning in, tuning out: The strange disappearance of social capital in America. Political science and politics, 28, pp. 664-683.

Putnam, R. D. (2004) Preface: Using social capital to help integrate planning theory, research, and practice. Journal of the American Planning Association, 70(2), Spring, pp. 142-192.

Rafaeli, A. \& Sutton, R. I. (1989). The expression of emotion in organizational life. Research in Organizational Behaviour, 11, pp. 1-42.

Rafaeli, A. \& Sutton, R. I. (1990). Busy stores and demanding customers: How do they affect the display of positive emotions. Academy of Management Journal, 33(3), pp. 623-637.

Rafaeli, A. \& Sutton, R. I. (1991). Emotional contrast strategies as means of social influence: Lessons from criminal interrogators and bill collectors. Academy of Management Journal, 34 (4), pp. 749-775. 
Reed, M. G. (2003). Taking stands: Gender and the sustainability of rural communities. Vancouver, BC: UBC Press.

Salovey, P. \& Mayer, J. D. (1990). Emotional intelligence. Imagination, Cognition, and Personality, 9 , pp.185-211.

Senge, P. M. (1992). The fifth discipline: The art and practice of the learning organization. Sydney: Random House Australia.

Simon, H. A. (1955). A behavioural model of rational choice. Quarterly Journal of Economics, 69, pp. 99118.

Stanley, R. O. \& Burrows, G. D. (2001). Varieties and functions of human emotion. In R. L. Payne \& C. L. Cooper (Eds.). Emotions at work: Theory, research and applications in management. (pp. 3-19). Chichester, England: Wiley.

Tanner, K. (2001). Developing a supportive organisational context for knowledge management: A conceptual framework. In F. Burstein \& H. Linger (Eds) Knowledge Management for Information Communities: Proceedings of the Australian Conference of Knowledge Management and Intelligent Decision Support, 4-5 December 2000, Melbourne, Australia. Melbourne: Australian Scholarly Publishing, pp. 56-94.

Tiedens, L. Z. (2000). Powerful emotions: The vicious cycle of social status positions and emotions. In N. M. Ashkanasy, C. E. J. Härtel, \& W. J. Zerbe, (Eds.). Emotions in the workplace: Research, theory and practice. (pp. 71-81). Westport, CT: Quorum Books.

Tobin, D. R. (1996). Transformational learning: Renewing your company through knowledge and skills. New York: John Wiley.

Tran, V. (1998). The role of the emotional climate in learning organizations. The Learning Organization, 5(2), pp. 99-103.

Van Maanen, J. \& Kunda, G. (1989). 'Real feelings': Emotional expression and organizational culture. Research in Organizational Behaviour, 11, pp. 43-103.

Waldron, V. R. (2000). Relational experiences and emotion at work. In S. Fineman (Ed.). Emotion in organizations. 2nd ed. (pp. 64-82). London; Thousand Oaks, CA: Sage Publications.

Weick, K. E. (1979). The social psychology of organizing. $2^{\text {nd }}$ ed. Reading, MA: Addison-Wesley.

Weisinger, H. (1998). Emotional intelligence at work: The untapped edge for success. San Francisco: Jossey-Bass.

Weiss, H. M. \& Brief, A. P. (2001). Affect at work: A historical perspective. In Payne, R. L. \& Cooper, C. L. (Eds.). Emotions at work: Theory, research and applications in management. (pp. 133-171). Chichester, England: Wiley.

Weiss, H. M. \& Cropanzano, R. (1996). Affective events theory: A theoretical discussion of the structure, causes and consequences of affective experiences at work. In R. I. Sutton and B. M. Staw (Eds.). Research in Organizational Behaviour, 18, pp. 1-74. Greenwich, CT: JAI Press.

WIRE_-Women's Information, Melbourne, Australia. Website: http://www.wire.org.au/

Zerbe, W .J. \& Härtel, C. E. J. (2000). Commentary: Emotions as mediators and moderators. In N. M.Ashkanasy, C. E. J. Härtel, \& W. J. Zerbe, (Eds.). Emotions in the workplace: Research, theory and practice. (pp. 156-161). Westport, CT: Quorum Books. 